\title{
Hazards and benefits of elective induction of labor at term
}

\author{
Perveena Fareed*, Suzaira Bashir, Sameer Ahmed Lone
}

Department of Obstetrics and Gynecology, GMC Srinagar, Jammu and Kashmir, India

Received: 03 August 2020

Accepted: 17 August 2020

\section{*Correspondence:}

Dr. Perveena Fareed,

E-mail: perveen.fareed21@gmail.com

Copyright: (c) the author(s), publisher and licensee Medip Academy. This is an open-access article distributed under the terms of the Creative Commons Attribution Non-Commercial License, which permits unrestricted non-commercial use, distribution, and reproduction in any medium, provided the original work is properly cited.

\section{ABSTRACT}

Background: The objective of this study was to compare the rates of caesarean section and neonatal outcome in patients with elective induction of labor compared to patients with spontaneous onset of labor.

Methods: Authors studied 200 patients with 100 in elective induction group and 100 in spontaneous onset laboring group. Two groups were compared with respect to demographic profile, basic examination, ultrasound findings, P/A, P/V findings, duration of labor, mode of delivery and neonatal outcome.

Results: Various parameters like age residence, per abdominal findings were comparable in two groups. Labor was not prolonged in study group compared to control group. Rate of caesarean section remained high in induction group (21\%) in comparison to spontaneous laboring group (4\%). Rate of instrumental deliveries did not differ significantly between the groups. 5 min Apgar score did not vary significantly; however, the NICU admission was higher in induction group compared to spontaneous laboring group. Duration of hospital stay was longer in study group.

Conclusions: Elective induction of labor has higher rates of caesarean deliveries. NICU admission was also longer in induction group.

Keywords: Apgar score, Caesarean section, Elective induction, Neonatal intensive care unit admission

\section{INTRODUCTION}

Elective induction of labor is by definition a medical intervention to initiate labor at a time than nature would have otherwise selected.

During the past 40 years labor induction has mostly involved combining the recognized advantages of physical manipulation with a pharmacological myometrial stimulant. During 1980 and 1990's patient's acceptance of when and how delivery was achieved became a significant and sometimes overpowering consideration. Many think that elective induction of labor exposes the women and her baby to cascade of related events each contributing its own hazard, culmination of which is less favourable than would be obtained if nature were allowed to follow its course. ${ }^{1-5}$ There can be no doubt that elective induction for convenience of practitioner or patient is becoming more prevalent.
Problems with induction stem from two sources: The physiology of initiating labor and the side effects of procedure and drugs. Starting or intensifying labor involves a complex cascade of feedback mechanisms that mutually reinforce and limit each other. It is an elegant and delicate dance of hormones and other substances between the baby who initiates and controls the process, and the mother. This is the reason why studies constantly show that inducing labor apart from the reason for induction considerably increases the likelihood of caesarean section in first time mothers. ${ }^{2,6,7}$

Second, all of the procedures and drugs used in inducing labor can have adverse effects.

Oxytocin can cause uterine hyperstimulation, fetal distress, low Apgar score, post-partum hemorrhage, neonatal jaundice and substantial increased likelihood of caesarean section in first time mothers. ${ }^{2,6,3,7-9}$ 
Prostaglandin E2 (dinoprostone) used for labor induction can also cause uterine hyperstimulation and fetal distress. In some cases, fetal distress can lead to caesarean section. The condition of the cervix or favourability is important to success of labor induction. ${ }^{11}$

Despite all these concerns many labors are electively induced. The advent of IV pumps to tightly control oxytocin dose and prostaglandin gel to soften the cervix has led obstetricians to believe that technology has conquered the problems of uterine hyperstimulation and failed induction.

Advanced scheduling of inductions has however encouraged presence of spouse, eased domestic arrangements, ensured attendance of patient's physician and avoided journeys during labor from distant places or in severe climatic conditions. Fatigue on the part of patient and her attendance is lessened with day time deliveries. The hospital staff gets benefitted not only from better use of staff and reduction of weekend and holiday workloads but from improved occupancy of beds with the levelling of the peaks and valleys associated with the deliveries after spontaneous onset of labor.

\section{Aims and objectives}

The objectives of this study were to determine whether elective induction of labor increases danger to mother and baby, and whether rate of caesarean section is increased or not, to determine whether elective induction of labor is associated with dangers to mother or baby in comparison to spontaneous onset. To assess is there an increased need for caesarean delivery consequent to induced labor, is there an increased rate of instrumental delivery in induced labors in comparison to spontaneous labor and to determine the incidence of transfer of baby to neonatal ward.

\section{METHODS}

This study was conducted in the department of obstetrics and gynecology GMC Srinagar over a period of one year from October 2018 to October 2019. Total of 200 patients were studied, 100 of which were pregnancies in which labor was induced electively at or after 38-39 weeks while 100 were pregnancies in which onset of labor was spontaneous. All the patients included in the study had term or post term primigravida singleton pregnancies with vertex presentation. Ethical clearance was taken from hospital ethical committee.

Detail history was taken, examination done and investigation ordered.

Elective induction was initiated by intra vaginal prostaglandin E2 or oxytocin intravenously as feasible.
A $0.5 \mathrm{mg}$ of prostaglandin E2 gel was used for cervical ripening. If there is no improvement in bishop score after 6 hours, second or third dose was used. Once patient went in active labor artificial rupture of membranes or augmentation with oxytocin was used if needed.

For induction of labor with oxytocin, oxytocin was started with low dose but escalated where there is no response. When optimal response achieved the administration of a particular concentration was continued.

During oxytocin induction rate of flow of infusion, number and duration of uterine contraction per ten minutes, fetal heart monitoring and assessment of progression of labor was done. Infusion was stopped if uterine contraction lasted more than 60 second and occurring frequently (every 2 min or less) and in uterine hypertonus.

In control patients with spontaneous labor augmentation with oxytocin or rupture of membranes was done. Labor was monitored.

\section{RESULTS}

Table 1 shows mean age in study group was $24.2 \pm 2.0$ years and $22.4 \pm 2.8$ years in control group. The difference was not significant.

As seen in Table 2 anaemia was significantly more prevalent in study group as compared to control group. Jaundice, edema and cyanosis was comparable in two groups.

The statistical difference in relation to presenting part in between the two groups was not significant. The presenting part was engaged in $29 \%$ in study group while it was $36 \%$ in control group. The difference in the two groups was not statistically significant.

Table 4 shows that membranes were present in all subjects in study group while as they were present in $68 \%$ in control group. The difference in relation to membranes was statistically significant. The bishop score was significantly better in study group as compared to control group. Less than 4 bishop score was seen in all subjects in study group whereas more than 4 bishop score was seen in $89 \%$ controls with no patient in study group having bishop score $>4$.

Assessment of liquor revealed adequate liquor in all study subjects while as it was adequate in $68 \%$ subjects in control group. The difference was statistically significant. The statistical difference in relation to placental localization in between the two groups was significant. 
Table 1: Demographic characteristics.

\begin{tabular}{|c|c|c|c|}
\hline Demographic characteristics & Study group & Control group & P value \\
\hline Age in years & & & \multirow{4}{*}{0.000} \\
\hline $20-24$ & 60 & 86 & \\
\hline $25-29$ & 40 & 6 & \\
\hline $30-34$ & 0 & 8 & \\
\hline Mean \pm SD & $24.2 \pm 2.0$ & $22.4 \pm 2.8$ & \\
\hline \multicolumn{3}{|l|}{ Residence } & \multirow{3}{*}{0.825} \\
\hline Urban & 11 & 12 & \\
\hline Rural & 89 & 88 & \\
\hline
\end{tabular}

Table 2: General physical examination.

\begin{tabular}{|c|c|c|c|c|}
\hline GPE & & Study group & Control group & $P$ value \\
\hline \multirow{2}{*}{ Anemia } & Yes & 14 & 4 & \multirow{2}{*}{0.014 (sig) } \\
\hline & No & 86 & 96 & \\
\hline Jaundice & Nil & 100 & 100 & 1.00 \\
\hline \multirow{2}{*}{ Edema } & Nil & 82 & 87 & \multirow{2}{*}{0.330} \\
\hline & Mild & 18 & 13 & \\
\hline Cyanosis & No & 100 & 100 & 1.000 \\
\hline
\end{tabular}

Table 3: Per abdomen examination.

\begin{tabular}{|lllll|}
\hline Per abdomen examination & & Study group & Control group & P value \\
\hline Fundal height & T/s & 100 & 100 & 1.000 \\
\hline Presenting part & Vertex & 100 & 100 & 1.000 \\
\hline \multirow{2}{*}{ Fetal heart sound } & Positive & 100 & 100 & 1.000 \\
\hline \multirow{2}{*}{ Engagement of presenting part } & Positive & 29 & 36 & 0.291 \\
\cline { 2 - 5 } & Negative & 71 & 64 & \\
\hline
\end{tabular}

Table 6 shows the higher rate of caesarean section in study group (21\%) as compared to $4 \%$ in control group. There were $12 \%$ instrumental deliveries in study group and $5 \%$ in control group.

Table 7 shows higher neonatal admission in 24 hours of life in study group compared to control group. Difference between the Apgar scores between the two groups was not statistically significant.

The mean duration of hospital stay in study group was $3.2 \pm 2.3$ whereas it was $2.3 \pm 1.2$ in control group. The statistical difference in relation to hospital stay in between the two groups was statistically significant.

Table 4: Per vaginum examination.

\begin{tabular}{|c|c|c|c|c|}
\hline \multicolumn{2}{|c|}{ Per vaginum examination } & Study group & Control group & P value \\
\hline \multirow{3}{*}{ Condition of cervix } & Os closed & 100 & 0 & \multirow{3}{*}{0.000 (sig) } \\
\hline & $2 \mathrm{~cm}$ & 0 & 43 & \\
\hline & $3 \mathrm{~cm}$ & 0 & 57 & \\
\hline \multirow{4}{*}{ Station of PP } & 0 & 29 & 36 & \multirow{4}{*}{0.075} \\
\hline & -1 & 24 & 31 & \\
\hline & -2 & 23 & 17 & \\
\hline & -3 & 24 & 16 & \\
\hline \multirow{2}{*}{ Membranes } & Present & 100 & 68 & \multirow{2}{*}{0.000 (sig) } \\
\hline & Absent & 0 & 32 & \\
\hline \multirow{2}{*}{ Bishop score } & $\leq 4$ & 100 & 11 & \multirow{2}{*}{0.000 ( $\mathrm{sig}$ ) } \\
\hline & $>4$ & 0 & 89 & \\
\hline
\end{tabular}


Table 5: Ultrasound findings.

\begin{tabular}{|c|c|c|c|c|}
\hline USG findings & & Study group & Control group & P value \\
\hline \multirow{3}{*}{$\begin{array}{l}\text { Gestational age in } \\
\text { weeks }\end{array}$} & $37-38$ & 54 & 35 & \multirow{3}{*}{0.007} \\
\hline & $38-39$ & 35 & 47 & \\
\hline & $39-40$ & 11 & 18 & \\
\hline \multirow{2}{*}{ Liquor } & Adequate & 100 & 68 & \multirow{2}{*}{$0.000(\mathrm{sig})$} \\
\hline & Inadequate & 0 & 32 & \\
\hline \multirow{4}{*}{ Placenta } & Fundal & 76 & 87 & \multirow{4}{*}{0.038 (sig) } \\
\hline & Right lateral & 14 & 9 & \\
\hline & Left lateral & 6 & 4 & \\
\hline & Low lying but away from os & 4 & 0 & \\
\hline
\end{tabular}

Table 6: Mode of delivery.

\begin{tabular}{|lllll|}
\hline Final outcome & & Study group & Control group & P value \\
\hline \multirow{3}{*}{ Mode of delivery } & Vaginal & 67 & 91 & 0.000 \\
\cline { 2 - 5 } & LSCS & 21 & 4 & 0.000 \\
\cline { 2 - 5 } & Instrumental & 12 & 5 & 0.076 (NS) \\
\hline
\end{tabular}

Table 7: Neonatal outcome.

\begin{tabular}{|llllll|}
\hline Neonatal out come & & Study group & Control group & P value \\
\hline \multirow{2}{*}{$\mathbf{5}$ min Apgar score } & $<7$ & 11 & 9 & \multirow{2}{*}{0.638} \\
\cline { 2 - 5 } & $\geq 7$ & 89 & 91 & \multirow{2}{*}{0.028 (sig) } \\
\cline { 2 - 5 } NICU admission & Yes & 20 & 9 & \\
\cline { 2 - 5 } & No & 80 & 91 & \\
\hline
\end{tabular}

Table 8: Comparison of hospital stay (days).

\begin{tabular}{|lllll|}
\hline Group & Minimum & Maximum & Mean+SD & P value \\
\hline Study group & 2 & 9 & $3.2 \pm 2.3$ & 0.001 (sig) \\
\hline Control group & 2 & 8 & $2.3 \pm 1.2$ & \\
\hline
\end{tabular}

\section{DISCUSSION}

The study entitled" hazards and benefits of elective induction of labour at term" was a prospective study conducted at LD hospital Srinagar. The primary focus of this study was to determine whether elective induction of labor is associated with dangers to mother or baby in comparison to labor of spontaneous onset.

The mean age of study population was $24.2 \pm 2$ years while in controls it was $22.4 \pm 2.8$ years. Authors found statically insignificant difference between the two groups.

In study group general physical examination showed anemia in 14 patients while in control group anaemia was seen in 4 patients. The difference was statically significant.

In study group $100 \%$ patients had term size fundal height, the presenting part was vertex and fetal heart sound was present while as in 29 such subjects presenting part was engaged and in rest 71 patients presenting part was unengaged. In control group 100\% subjects had term size fundal height, presenting part was vertex and fetal heart sound was present while as in 36 such subjects the presenting part was engaged while as in rest 64 it was unengaged. The difference was not statically significant.

This study findings were comparable to studies done by Cammu et al. ${ }^{12}$ Glantz et al compared labor outcomes in induced and spontaneous group respectively. ${ }^{5}$

Authors found statistically significant difference in relation to cervical dilatation, membrane status and bishop score between the two groups while as no difference was seen in relation to station of presenting part. Jhonson et al evaluated bishop score at initiation of induction as risk factor for cesarean section. ${ }^{10}$ The cesarean delivery rate was $31 \%$ among patients with bishop score less than 5 at induction as against $18.1 \%$ for patients with bishop score of more than 5 .

In this study authors found statically significant difference in relation to gestational age, amount of liquor and placenta localization in between the two groups. This study was comparable to the study done by Vahratian et 
al. ${ }^{9}$ In this study the minimum duration of active labor in hours was 2 and maximum 12. The mean duration of active labor was $7.1 \pm 1.4$ while in control group it was $6.8 \pm 1.5$. the difference was not statistically significant.

In this study 67 patients delivered vaginally, 21 has cesarean section, 12 had instrumental deliveries while in control group $91 \%$ delivered vaginally, $4 \%$ had cesarean section and $5 \%$ had instrumental deliveries. The difference was statistically significant. Turcot et al reported that odds ratio for operative deliveries increased after elective induction of labor compared to labor of spontaneous onset. ${ }^{11}$ Dublin et al reported an increase in instrumental deliveries in electively induced labor compared to spontaneous onset (19\% versus $15 \%){ }^{3}$

Maslow et al reported two-fold higher risk for cesarean delivery in elective induction of labor. ${ }^{6}$ Cammu et al, reported $9.9 \%$ cesarean delivery and $31.6 \%$ instrumental delivery in electively induced labor against $6.5 \%$ cesarean rate and $29.1 \%$ instrumental delivery rate in spontaneous labor. ${ }^{12}$

Authors found no statistically significant difference I relation to 5-minute Apgar score in between the two groups while as significant statistical difference was observed in neonatal admission during 24 hours of life in between the two groups. This study results were comparable with the available literature. Cammu et al reported that $10.7 \%$ babies born after elective induction were admitted to NICU as against $9.4 \%$ born after spontaneous labor. ${ }^{12}$ Vrouenraets et al reported a higher NICU admission after elective induction compared to spontaneous labor. ${ }^{8}$

In this study authors found significant statistical difference in relation to duration of hospital stay in between the two groups. This study findings are comparable to studies done by Vrouenraets et al who observed a longer maternal hospital stay with elective induction as compared to labor of spontaneous onset. ${ }^{8}$

\section{CONCLUSION}

It is concluded from this study that with elective induction, labor is not prolonged; however, the rate of caesarean deliveries remained high. The neonatal outcome generally remained unaffected expect for a higher rate of neonatal admission in study group.

Funding: No funding sources Conflict of interest: None declared

Ethical approval: The study was approved by the Institutional Ethics Committee

\section{REFERENCES}

1. Smith LP, Nagourney BA, McLean FH, Usher RH. Hazards and benefits of elective induction of labor. Am J Obstet Gynaecol. 1984;148:579.

2. Yeast JD, jones A, Poskin M. Induction of labor and relationship to cesarean delivery. A review of 7001 consective inductions. Am J Obstet Gynaecol. 1999;180(3 pt 1):628-33.

3. Dublin S, Lydon-Rochelle M, Kaplan RC, Watts $\mathrm{DH}$, Critchlow CW. Maternal and neonatal outcomes after induction of labor without an identified indication. Am J Obstet Gynaecol. 2000;183(4):98694.

4. Kaufman KE, Bailit JL, Grobman W. Elective induction: an analysis of economic and health consequences. Am J Obstet Gynecol. 2002;187(4):858-63.

5. Glantz JC. Elective induction versus spontaneous labor associations and outcomes. J Rep Med. 2005;50(4):235-40.

6. Maslow AS, Sweeny AL. Elective induction of labor as risk factor for caesarean delivery among low risk women at term. Obstet Gynecol. 2000;95(6):917-22.

7. Van Gemund N, Hardeman A, Scherjon SA, Kanhai HH. Intervention rates after elective induction of labor compared to labor with a spontaneous onset. A matched cohort study. Gynaecol Obstet Invest. 2003;56(3):133-8.

8. Vrouenraets FP, Roumen FJ, Dehling CJ, VAnden akker ES, Aarts MJ, Scheve EJ. Bishops score and risk of cesarean delivery after induction of labor in nulliparous women. Obstet Gynaecol. 2005;105(4)688-9.

9. Vahratain A, Zhang J, Troendle JF, Sciscione AC, Hoffman MK. Labor progression and risk of cesarean delivery in electively induced nulliparas. Obstet Gynaecol. 2005;105(4):688-9.

10. Jhonson DP, Davis NR, Brown AJ. Risk of cesarean delivery after induction at term in nulliparos women with an unfavourable cervix. Am J Obstet Gynaecol. 2003;188(6):1565-9.

11. Turcot L, Marcoux S, Fraser WD. Multivarait analysis of risk factors for operative delivery in nulliparos women. Am J Obstet Gynaecol. 1997;176(2):395-402.

12. Cammu H, Martens G, Ruyssinck G, Mijj. Outcome after elective labor induction in nulliparos women. A matched cohort study. Am J Obstet Gynaecol. 2000;186(2):240-4.

Cite this article as: Fareed $\mathrm{P}$, Bashir S, Lone SA. Hazards and benefits of elective induction of labor at term. Int J Reprod Contracept Obstet Gynecol 2020;9:3626-30. 